\title{
Hippocampus and Pavlovian Fear Conditioning in Rats: Muscimol Infusions Into the Ventral, but Not Dorsal, Hippocampus Impair the Acquisition of Conditional Freezing to an Auditory Conditional Stimulus
}

\author{
Stephen Maren and William G. Holt \\ University of Michigan
}

\begin{abstract}
The authors compared the effects of pharmacological inactivation of the dorsal hippocampus (DH) or ventral hippocampus $(\mathrm{VH})$ on Pavlovian fear conditioning in rats. Freezing behavior served as the measure of fear. Pretraining infusions of muscimol, a $\mathrm{GABA}_{\mathrm{A}}$ receptor agonist, into the $\mathrm{VH}$ disrupted auditory, but not contextual, fear conditioning; DH infusions did not affect fear conditioning. Pretesting inactivation of the $\mathrm{VH}$ or $\mathrm{DH}$ did not affect the expression of conditional freezing. Pretraining electrolytic lesions of the $\mathrm{VH}$ reproduced the effects of muscimol infusions, whereas posttraining $\mathrm{VH}$ lesions disrupted both auditory and contextual freezing. Hence, neurons in the VH are importantly involved in the acquisition of auditory fear conditioning and the expression of auditory and contextual fear under some conditions.
\end{abstract}

An abundance of evidence indicates that the hippocampus is importantly involved in associative learning and memory (Anagnostaras, Gale, \& Fanselow, 2001; Douglas, 1967; Eichenbaum, 1997; Honey \& Good, 2000; Maren \& Holt, 2000; Morris \& Frey, 1997; O’Keefe \& Nadel, 1978; O’Reilly \& Rudy, 2001; Qin, McNaughton, Skaggs, \& Barnes, 1997; Squire \& Zola-Morgan, 1991; Zola-Morgan \& Squire, 1993). In rodents, much of this work has focused on the contribution of the hippocampus to spatial learning and memory. Recently, however, considerable interest has emerged in the role of the hippocampus in memory for context, which defines the temporal, spatial, internal, and environmental stimuli present at the time of any learning episode. Like spatial learning and memory, the encoding and storage of contextual representations is often viewed as a form of declarative learning insofar as contexts define the relationships between stimuli and the time and place that episodes occur (Fanselow, 2000; O'Reilly \& Rudy, 2001).

Several recent studies have revealed an important role for the hippocampus in the acquisition of contextual representations in both rats and humans (Chun \& Phelps, 1999; Holland \& Bouton, 1999). In this regard, the involvement of the hippocampus in contextual learning has received considerable support from studies of Pavlovian fear conditioning in rats (Anagnostaras et al., 2001; Maren, Anagnostaras, \& Fanselow, 1998; Rudy \& O'Reilly, 1999; Sanders, Wiltgen, \& Fanselow, 2003). In this form of learning,

Stephen Maren, Department of Psychology, Neuroscience Program, University of Michigan; William G. Holt, Department of Psychology, University of Michigan.

This research was supported by Grant R29MH57865 from the National Institute of Mental Health. We thank Kevin Corcoran for helpful comments on a previous version of this article.

Correspondence concerning this article should be addressed to Stephen Maren, Department of Psychology, University of Michigan, 525 East University Avenue, Ann Arbor, MI 48109-1109. E-mail: maren@umich .edu animals come to fear innocuous conditional stimuli (CSs; tones or contexts) that predict the onset of aversive unconditional stimuli (USs; footshocks). Several studies have found that lesions of the dorsal hippocampus (DH) produce deficits in the acquisition of conditional fear to the context in which aversive conditioning occurs, while having little effect on fear to discrete CSs, including tones (Phillips \& LeDoux, 1992, 1994; Selden, Everitt, Jarrard, \& Robbins, 1991; Young, Bohenek, \& Fanselow, 1994). Moreover, DH lesions produce a time-limited retrograde amnesia for contextual information when lesions are made after fear conditioning (Anagnostaras, Maren, \& Fanselow, 1999; Kim \& Fanselow, 1992; Maren, Aharonov, \& Fanselow, 1997). It is not surprising that these data have encouraged the development of fear conditioning as an animal model to explore the hippocampal amnesic syndrome in humans (Anagnostaras et al., 2001).

Nonetheless, there is considerable debate concerning the exact contribution of the hippocampus to the acquisition versus the expression of contextual fear, on the one hand, and its selectivity in processing contextual versus discrete CSs, on the other (Anagnostaras, Gale, \& Fanselow, 2002; Bast, Zhang, \& Feldon, 2001a; Gewirtz, McNish, \& Davis, 2000; Maren et al., 1998). Several studies reveal that the method by which hippocampal lesions are made is a critical variable in determining the effect of hippocampal damage on contextual conditioning. Electrolytic, but not neurotoxic, DH lesions produce deficits in the acquisition of contextual freezing (Cho, Friedman, \& Silva, 1999; Frankland, Cestari, Filipkowski, McDonald, \& Silva, 1998; Gisquet-Verrier, Dutrieux, Richer, \& Doyere, 1999; Kim, Rison, \& Fanselow, 1993; Maren et al., 1997; Phillips \& LeDoux, 1992; but see Young et al., 1994). Furthermore, auditory fear conditioning is not necessarily immune to hippocampal damage. Two laboratories have found that neurotoxic hippocampal lesions produce deficits in freezing to auditory CSs under a variety of conditions (Maren et al., 1997; Richmond et al., 1999). In both cases, the volume and localization of hippocampal lesions is an important variable in determining their effects on fear conditioning. Either (a) large lesions of the hip- 
pocampus that include both the $\mathrm{DH}$ and the ventral division of the hippocampus ( $\mathrm{VH}$ ) or (b) restricted lesions of the $\mathrm{VH}$ alone yield deficits in auditory fear conditioning (Maren, 1999b; Richmond et al., 1999). Large VH lesions may also yield deficits in the acquisition and expression of contextual fear conditioning (Maren, 1999b; Richmond et al., 1999). Hence, the exact role of the hippocampus in the acquisition and expression of Pavlovian fear conditioning to contextual and discrete CSs is far from clear.

One possibility is that there is a functional dissociation between the dorsal and ventral hippocampus in Pavlovian fear conditioning. Indeed, the dorsal and ventral hippocampus appear to play different roles in a variety of learning and memory tasks, such as the Morris water maze. Furthermore, DH and VH lesions have different effects on tests of unconditioned anxiety (Bannerman et al., 2002, 2003; Kjelstrup et al., 2002). In Pavlovian fear conditioning, total or ventral hippocampal lesions produce robust deficits in freezing to auditory stimuli (Maren, 1999b; Richmond et al., 1999), whereas dorsal hippocampal lesions typically spare auditory fear conditioning (Anagnostaras et al., 1999; Kim \& Fanselow, 1992; Phillips \& LeDoux, 1992). In contrast, both ventral and dorsal hippocampal lesions impair contextual fear conditioning, particularly if they are made after training (Anagnostaras et al., 1999; Bannerman et al., 2003; Kim \& Fanselow, 1992; Maren, 1999b; Maren et al., 1997; Richmond et al., 1999). Hence, an intriguing possibility is that the ventral hippocampus has a greater role in auditory fear conditioning than the dorsal hippocampus.

Yet, one problem with interpreting the effects of permanent brain lesions on fear conditioning (and on any learning and memory task, for that matter) is the potential for postsurgical recovery of function of the damaged brain area, recruitment of other neural systems to the task, or adoption of alternative behavioral strategies (and neural systems). All of these phenomena would tend to mask involvement of the hippocampus in the associative process under study and may yield normal behavioral performance in a hippocampal animal. In fact, several studies now suggest that contextual fear conditioning can be supported by either elemental or conjunctive representations of context, with only the latter requiring the hippocampus (Maren et al., 1997; Rudy, Barrientos, \& O'Reilly, 2002; Rudy \& O'Reilly, 1999). This may account for the profound differences in the effects of pre- versus posttraining DH lesions on contextual freezing. Conversely, permanent brain lesions may yield performance deficits that masquerade as impairments in learning or memory. This may be particularly problematic with the increases in locomotor activity that accompany hippocampal lesions (Gewirtz et al., 2000; McNish, Gewirtz, \& Davis, 1997, 2000), although increases in motor activity and freezing deficits are dissociable in animals with hippocampal damage (Maren, 1999b; Maren et al., 1998).

To overcome some of these problems, we have used intracranial infusions of muscimol, a $\mathrm{GABA}_{\mathrm{A}}$ agonist, to examine the contribution of the hippocampus to Pavlovian fear conditioning (Corcoran \& Maren, 2001; Holt \& Maren, 1999). We have focused on the role of the hippocampus in the retrieval of context-specific memories. This work has revealed that $\mathrm{GABA}_{\mathrm{A}}$ receptors in the $\mathrm{DH}$ are involved in the context-specificity of fear to an auditory CS but are not directly involved in the expression of either contextual or auditory freezing per se. Yet, we have not examined whether intrahippocampal muscimol affects the acquisition of contextual and auditory fear conditioning. Although recent studies have examined the influence of reversible inactivation of the $\mathrm{VH}$ or intra-VH infusions of $\mathrm{N}$-methyl-D-aspartate (NMDA) receptor antagonists on the acquisition of Pavlovian fear conditioning (Bast, Zhang, \& Feldon, 2001b; Zhang, Bast, \& Feldon, 2001), reversible lesion techniques have not been used to directly compare the dorsal and ventral hippocampal contributions to contextual and auditory fear conditioning. Therefore, in the present report, we used intrahippocampal infusions of muscimol to directly assess the contribution of the $\mathrm{DH}$ and $\mathrm{VH}$ to the acquisition of contextual and auditory fear conditioning in rats. We used a dose and volume of muscimol that produces robust neuronal inactivation, at least in the thalamus and cortex (Edeline, Hars, Hennevin, \& Cotillon, 2002; Martin, 1991). We report that muscimol infusions into the VH, but not the DH, yield impairments in the acquisition of fear conditioning and that this impairment is selective to an auditory CS.

\section{General Method}

\section{Subjects}

The subjects were 139 adult male Long-Evans rats (200-224 g) obtained from a commercial supplier (Harlan Sprague-Dawley, Indianapolis, IN). After arrival, the rats were individually housed in standard Plexiglas hanging cages on a 14:10-hr light-dark cycle (lights on at 7:00 a.m.) and provided free access to food and tap water. After housing, rats were handled for $30 \mathrm{~s}$ per day for 5 days to acclimate them to the experimenters. All of the procedures in this report were approved by the University Committee on Use and Care of Animals (UCUCA) at the University of Michigan.

\section{Behavioral Apparatus}

All training and testing occurred in eight identical observation chambers $(30 \times 24 \times 21 \mathrm{~cm}$; MED-Associates Inc., Burlington, VT) located in sound-attenuating cabinets in an isolated room. The chambers were constructed of aluminum (two side walls) and Plexiglas (rear wall, ceiling, and hinged front door). The floor of each chamber consisted of 19 stainless steel rods (4-mm diameter) spaced $1.5 \mathrm{~cm}$ apart (center to center). The rods were wired to a shock source and solid-state grid scrambler (MEDAssociates, Burlington, VT) for the delivery of footshock USs. A speaker for delivering acoustic CSs was mounted to a grating on one wall of each chamber.

Each conditioning chamber was situated on a load-cell platform that recorded chamber displacement in response to each rat's motor activity. The output of each chamber's load cell was amplified (vernier knob $=8$ ) at a level that was previously determined to optimize the detection of freezing behavior (somatomotor immobility, except that necessitated by breathing; Maren, 1998). For each chamber, load-cell voltage (load-cell V) was digitized at $5 \mathrm{~Hz}$, yielding one observation per rat every $200 \mathrm{~ms}$ (300 observations/rat/minute). In all experiments, freezing was quantified by computing the number of observations for each rat that had a value less than the freezing threshold (load-cell activity $=5$; animals exhibit freezing when load-cell activity is at or below this value; see Maren, 1998). To avoid counting momentary inactivity as freezing, we only scored an observation as freezing if it fell within a contiguous group of at least five observations that were all less than the freezing threshold. Thus, freezing was only scored if the rat was immobile for at least $1 \mathrm{~s}$. For each session, the freezing observations were transformed to a percentage of total observations.

Two experimental contexts were used in all of the experiments. For the training context, the chambers were cleaned with a $5 \%$ ammonium hydroxide solution, and stainless steel pans with a thin layer of the same 
solution were placed under the grid floors before rats were placed in the chambers. Illumination was provided by both the room lights and a small stimulus light $(15 \mathrm{~W})$ in each chamber, and background noise $(65 \mathrm{~dB}$, A-scale) was supplied by ventilation fans in each chest. For the context in which auditory extinction tests were conducted, $1 \%$ acetic acid was used to clean the chambers and was placed in the pans beneath the grid floors. Illumination was provided by a dim red light $(30 \mathrm{~W})$ in the room, and ventilation fans were turned off.

\section{Histology}

Histological verification of cannula placement was performed after behavioral testing. Rats were perfused across the heart with $0.9 \%$ saline followed by $10 \%$ Formalin. Brains were removed from the skull and placed in $10 \%$ Formalin for 2 days and $10 \%$ Formalin/30\% sucrose until sectioning. Coronal sections (40 $\mu \mathrm{m}$ thick, taken every $120 \mu \mathrm{m})$ were cut on a cryostat $\left(-18^{\circ} \mathrm{C}\right)$ and wet mounted on glass microscope slides with $95 \%$ ethanol. After drying, sections were stained with $0.25 \%$ thionin to visualize cell bodies. The tips of the injection cannulas were reconstructed on stereotaxic atlas templates (Swanson, 1998). If the injector tip was not visible, it was estimated from the location of the guide cannula.

\section{Data Analysis}

Freezing was calculated as a percentage of total observations, a probability estimate that is amenable to analysis with parametric statistics. Probability estimates of freezing were analyzed using analysis of variance (ANOVA). Post hoc comparisons in the form of Fisher's protected least significant difference (PLSD) tests were performed on the freezing averages after a significant omnibus $F$ ratio. All data are represented as means, plus or minus the standard errors of the means (SEMs).

\section{Experiment 1}

The aim of Experiment 1 was to compare the effects of pretraining infusions of muscimol into the $\mathrm{DH}$ or $\mathrm{VH}$ on the acquisition of Pavlovian fear conditioning. Rats with cannulas aimed at the basolateral amygdala (BLA) were included to serve as a comparison group demonstrating the deleterious effects of muscimol on the acquisition of both contextual and auditory fear conditioning (Helmstetter \& Bellgowan, 1994; Maren, Yap, \& Goosens, 2001; Muller, Corodimas, Fridel, \& LeDoux, 1997). Rats were infused with muscimol or vehicle shortly before fear conditioning. Retention of fear was assessed in separate context and tone extinction tests conducted 24 and $48 \mathrm{hr}$ following conditioning, respectively. Freezing served as the measure of fear.

\section{Method}

Subjects and design. Fifty-seven rats received surgical implantation of stainless steel cannulas aimed at the $\mathrm{DH}, \mathrm{VH}$, and BLA. Rats in each group were randomly assigned to receive intracranial infusions of muscimol or the saline vehicle solution $20 \mathrm{~min}$ before fear conditioning (i.e., pretraining infusions). Two subjects were excluded because of inaccurate cannula placements. The vehicle animals for each anatomical placement $(\mathrm{DH}, \mathrm{VH}$, and BLA) were collapsed to form one control group because there were no significant differences between the groups during either training, $F(2$, $17)=0.69$, or extinction testing: context, $F(2,17)=1.40$; tone, $F(2,17)=$ 2.92. This yielded the following groups: $\mathrm{VEH}(n=20), \mathrm{DH}(n=11), \mathrm{VH}$ $(n=14)$, and BLA $(n=10)$.

Surgery. One week before behavioral testing, rats were implanted with bilateral guide cannulas (23 gauge, $12 \mathrm{~mm}$; Small Parts, Clear Lakes, FL) aimed at the DH $(3.8 \mathrm{~mm}$ posterior to bregma, $2.5 \mathrm{~mm}$ lateral to the midline, $1.8 \mathrm{~mm}$ ventral to dura), $\mathrm{VH}(6.3 \mathrm{~mm}$ posterior to bregma, $5.0 \mathrm{~mm}$ lateral to the midline, $5.0 \mathrm{~mm}$ ventral to dura), or BLA (2.3 $\mathrm{mm}$ posterior to bregma, $5.0 \mathrm{~mm}$ lateral to the midline, $6.3 \mathrm{~mm}$ ventral to dura). Rats were anesthetized with sodium pentobarbital $(65 \mathrm{mg} / \mathrm{kg}$ ip) and were administered atropine methyl nitrate $(0.04 \mathrm{mg} / \mathrm{kg}$ ip) to prevent airway obstruction. After being mounted in a stereotaxic apparatus (Kopf Instruments, Tujunga, CA), the scalp was incised and retracted, and lambda and bregma were placed in the same horizontal plane. Small burr holes (1-mm diameter) were drilled for placement of the guide cannulas and three small jeweler's screws. The guide cannulas were lowered, and dental acrylic was applied to the skull to hold the cannulas in place. After surgery, dummy cannulas (28 gauge, $12 \mathrm{~mm}$; Small Parts, Clear Lakes, FL) were inserted into the guide cannulas, and the rats were returned to their home cages. The dummy cannulas were replaced every other day during the week of recovery.

Drug infusion. Pairs of rats were transported to an isolated room in plastic buckets containing a thin layer of pine shavings. Dummy cannulas were removed from each rat and injection cannulas extending $1 \mathrm{~mm}$ past the end of the guide cannulas were inserted. The injection cannulas (28 gauge, $13 \mathrm{~mm}$; Small Parts, Clear Lakes, FL) were connected to a $10 \mu \mathrm{l}$ Hamilton syringe via polyethylene tubing (PE-20; Fisher, Pittsburgh, PA) and mounted in an infusion pump (Harvard Apparatus, South Natick, MA). Rats were infused with either vehicle (VEH; 0.9\% sterile saline) or muscimol ( $1 \mu \mathrm{g} / \mu \mathrm{l}$; Sigma Chemical, St. Louis, MO). The infusion rate was $0.16 \mu \mathrm{l} / \mathrm{min}$, and the duration of the infusion was $1 \mathrm{~min}$ and $34 \mathrm{~s}$. Thus, a total volume of $0.25 \mu \mathrm{l}$ was infused per hemisphere $(0.25 \mu \mathrm{g}$ of muscimol per infusion site). During this time, rats were permitted to explore freely within the buckets; however, they were distracted when attempting to groom because grooming often dislodged the injection cannulas. After the pumps were turned off, 1 min was allowed for diffusion before the injectors were removed. Rats were returned to their home cages and transported to the conditioning chambers $20 \mathrm{~min}$ after the infusion.

Conditioning and testing procedure. Twenty minutes after drug infusion, the rats were placed in the conditioning chambers; the chamber position was counterbalanced for each squad and group. The rats received five tone $(10-\mathrm{s}, 90-\mathrm{dB}, 2-\mathrm{kHz})$-footshock $(2-\mathrm{s}, 1.0-\mathrm{mA} ; 70-\mathrm{s}$ intertrial interval) trials, $3 \mathrm{~min}$ after being placed in the chambers. The onset of the footshock US commenced at the offset of the tone CS. Sixty seconds after the final shock, the rats were returned to their home cages. Freezing was measured on the conditioning day as an index of short-term memory. One day after training, fear conditioning to the conditioning context was assessed by returning the rats to the conditioning chambers and measuring freezing behavior during an 8-min extinction test. Twenty-four hours after the context extinction test, fear to the tone CS was measured by placing the rats in a novel context and presenting an 8-min tone 2 min after placement in the context. During both the conditioning and extinction sessions, each rat's activity was monitored continuously using the data acquisition system described in the General Method section.

\section{Results and Discussion}

Histology. High-resolution scans of thionin-stained sections from three representative rats are shown in Figure 1. These sections illustrate typical cannula placements in each of the brain areas targeted in Experiments 1 and 2. Figure 2 shows the cannula placements for all of the rats in Experiment 1 superimposed on stereotaxic templates (Swanson, 1998). As shown, the cannula placements were bilaterally symmetrical and clustered in the targeted brain areas. Placements in the DH were centered on hippocampal area CA1 and the dentate gyrus, placements in the $\mathrm{VH}$ were centered on the caudal dentate gyrus and ventral subiculum, and placements in the BLA were centered on the lateral and basolateral nuclei of the amygdala. 

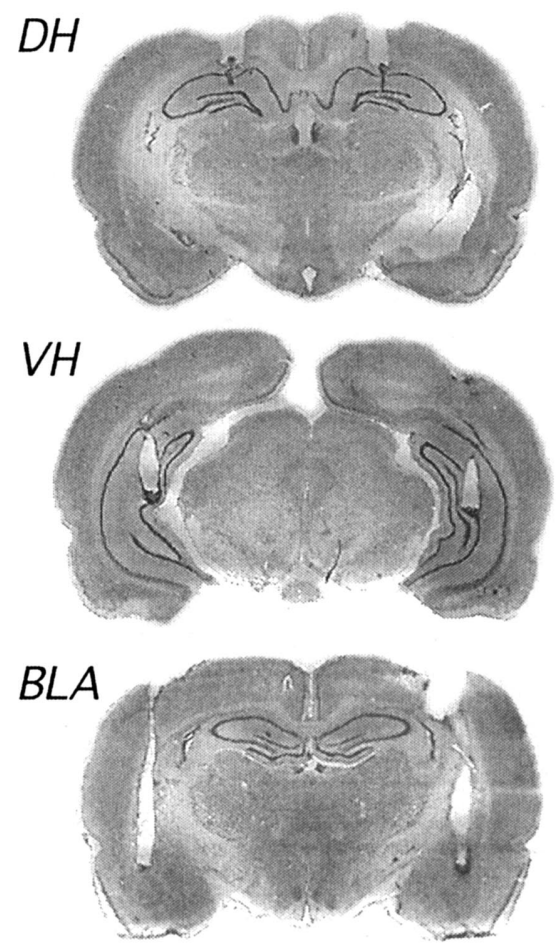

Figure 1. High-resolution scans of thionin-stained coronal sections from 3 rats with cannula target at the dorsal hippocampus (DH), ventral hippocampus (VH), and basolateral complex of the amygdala (BLA). Guide cannula tracks penetrate each of the targeted brain areas, and in some cases (e.g., DH) short (1 mm) injector tracks emerge beyond the end of the guide cannula tracks.

Behavior. To ascertain the effects of intracranial muscimol infusions on unconditioned freezing and activity, we examined these behaviors during the 3-min preshock period during the conditioning session. Freezing and activity prior to footshock during the fear conditioning session are shown in Figures $3 \mathrm{~A}$ and $3 \mathrm{~B}$, respectively. There was little conditional freezing prior to the delivery of footshock (Figure 3A). Nonetheless, there was a nearly significant group difference in this measure, $F(3,51)=2.59, p=$ .06. Post hoc comparisons $(p<.05)$ indicated that rats in the $\mathrm{DH}$ and BLA groups exhibited significantly more preshock freezing than rats in the saline (SAL) group. Rats in the VH group did not differ from SAL controls. This suggests that muscimol decreased overall activity levels, resulting in slightly higher levels of preshock freezing. However, an analysis of the activity did not reveal significant differences between the groups (see Figure 3B), $F(3$, $51)=0.33$. Hence, muscimol in the DH and BLA slightly increased freezing, without affecting overall activity levels.

Freezing during the entire conditioning session is shown in Figure 4. Compared with the 3-min preshock period (Pre), footshock reliably increased freezing in all of the groups across all of the 1-min postshock intervals following each conditioning trial, main effect of trial, $F(5,255)=20.0, p<.0001$. There were no differences between the groups in the total level of freezing during the conditioning session-nonsignificant main effect of group, $F(3,51)=0.90$ - or in the pattern of freezing across training trials: nonsignificant Group $\times$ Trial interaction, $F(15,255)=1.1$.
Thus, whereas muscimol in the BLA and DH produced mild, but significant, enhancements in preshock freezing, they did not reliably affect postshock freezing. The failure of intra-BLA muscimol to disrupt immediate postshock freezing is interesting in light of other data suggesting that this measure of conditioning is sensitive to either intra-BLA infusion of NMDA receptor antagonists (Maren, Aharonov, Stote, \& Fanselow, 1996) or BLA lesions (Maren, Aharonov, \& Fanselow, 1996). This suggests a different role for $\mathrm{GABA}_{\mathrm{A}}$ and NMDA receptors in the BLA in the mediation of immediate postshock freezing.

Conditional freezing during the context and tone extinction tests is shown in Figure 5. There were robust group differences in the levels of freezing behavior during both tests. During the context extinction test, rats in the BLA group exhibited a severe deficit in freezing, which replicates previously reported data (Helmstetter \&

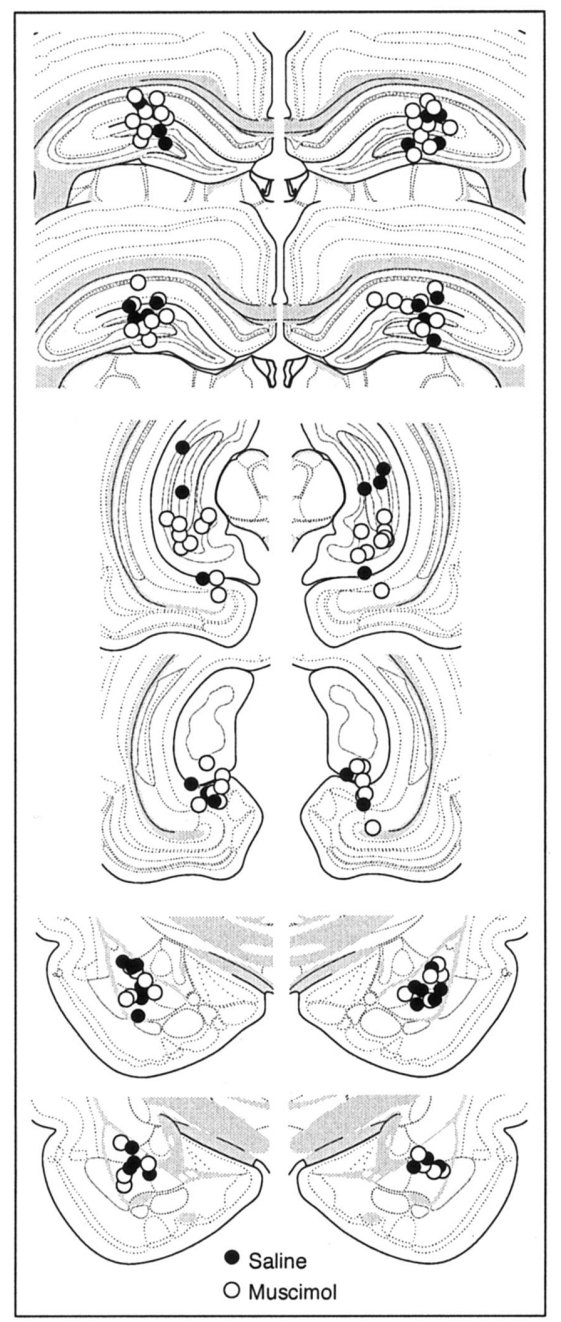

Figure 2. Schematic representation of cannula placements in the dorsal hippocampus (top), ventral hippocampus (middle), and basolateral complex of the amygdala (bottom) for Experiment 1. For each brain area, rats were infused with either saline or muscimol. Coronal brain section images are reprinted from Brain Maps: Structure of the Rat Brain, 2nd ed., L. W. Swanson, Levels 28, 29, 31, 32, 39, and 40, Copyright 1998, with permission from Elsevier. 
A

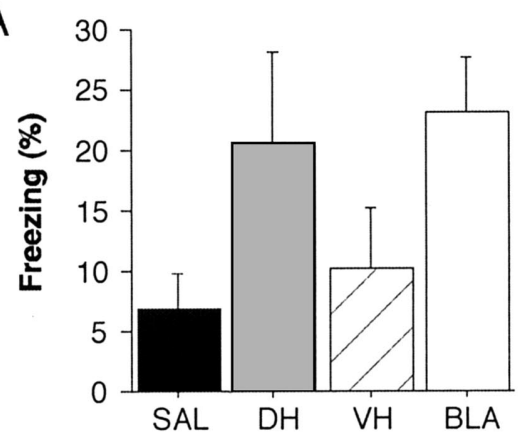

$\mathrm{B}$

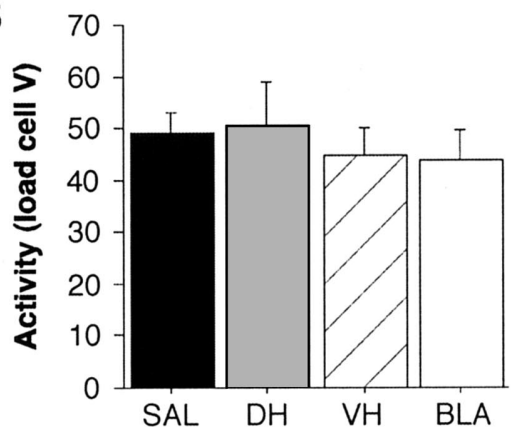

Figure 3. Effects of pretraining muscimol infusions into the dorsal hippocampus $(\mathrm{DH})$, ventral hippocampus $(\mathrm{VH})$, or basolateral complex of the amygdala (BLA) on preshock freezing and motor activity on the conditioning day in Experiment 1. A: Mean ( $\pm S E M$ ) percentage of freezing during the 3-min preshock period during the fear-conditioning session in rats that received intracranial muscimol infusions into the $\mathrm{DH}, \mathrm{VH}$, or BLA; control rats receiving saline (SAL) infusions into these brain areas were collapsed into a single group. B: Mean $( \pm S E M)$ motor activity (load cell voltage $[\mathrm{V}]$ ) during the 3-min preshock period on the conditioning day in rats that received intracranial muscimol infusions into the $\mathrm{DH}, \mathrm{VH}$, or BLA; control rats receiving saline infusions into these brain areas were collapsed into a single group.

Bellgowan, 1994; Muller et al., 1997). However, rats in the DH and $\mathrm{VH}$ groups exhibited levels of freezing similar to that in the $\mathrm{SH}$ group. A one-way ANOVA performed on the freezing data averaged across the 8-min test confirmed these impressions and revealed a significant main effect of group, $F(3,51)=8.32, p<$ .0001 . Post hoc comparisons $(p<.05)$ indicated that the BLA group differed significantly from rats in all of the other groups, which did not differ from one another. It is important to note that intrahippocampal infusions of muscimol before fear conditioning did not disrupt the acquisition of contextual fear conditioning.

Noteworthy, as shown in Figure 5, acquisition of conditional freezing to the tone CS was impaired by both ventral hippocampal and amygdala muscimol infusions. As with the context test, intraamygdala muscimol infusions prior to fear conditioning produced a complete deficit in the acquisition of auditory fear conditioning. Moreover, infusions of muscimol into the $\mathrm{VH}$, but not the $\mathrm{DH}$, produced an impairment in tone-elicited freezing during the extinction test. These impressions were confirmed by a significant main effect of group in the one-way ANOVA performed on the freezing data averaged across the 8-min tone test, $F(3,51)=5.51$, $p<.005$. Post hoc comparisons revealed that both the $\mathrm{VH}$ and BLA groups were significantly lower than the $\mathrm{SH}$ and $\mathrm{DH}$ groups,

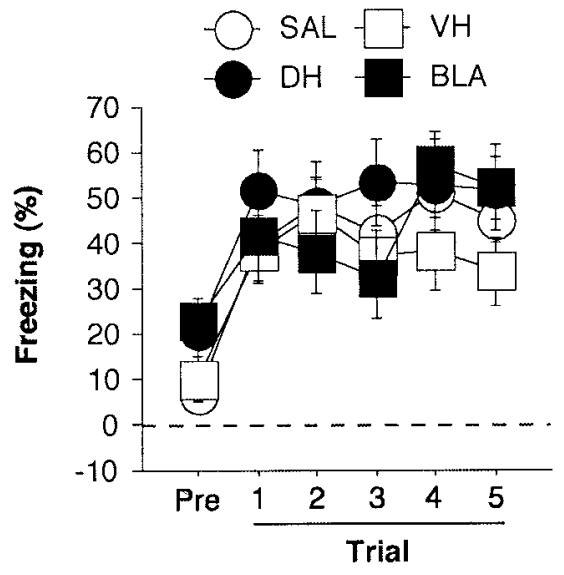

Figure 4. Effects of pretraining muscimol infusions into the dorsal hippocampus $(\mathrm{DH})$, ventral hippocampus $(\mathrm{VH})$, or basolateral complex of the amygdala (BLA) on preshock (Pre) and immediate postshock freezing on the conditioning day in Experiment 1. Mean ( $\pm S E M$ ) percentage of freezing during the 3-min preshock period (same as in Figure 2A) and five 1 -min postshock periods in rats that received intracranial muscimol infusions into the $\mathrm{DH}, \mathrm{VH}$, or BLA; control rats receiving saline (SAL) infusions into these brain areas were collapsed into a single group.

and neither the former nor the latter pair of groups differed from one another. It is also interesting to note that the deficit in tone freezing achieved with VH muscimol infusions was not as severe as the deficit produced by BLA muscimol infusions. Indeed, VH rats exhibited substantial freezing to the tone $\mathrm{CS}$ during the 1st min of the tone test. An analysis of the first $30 \mathrm{~s}$ on the tone extinction test revealed that only BLA rats differed from controls, $F(3,51)=$ 5.6, $p<.005$; Fisher's PLSD, $p<.05$. That is, VH muscimol

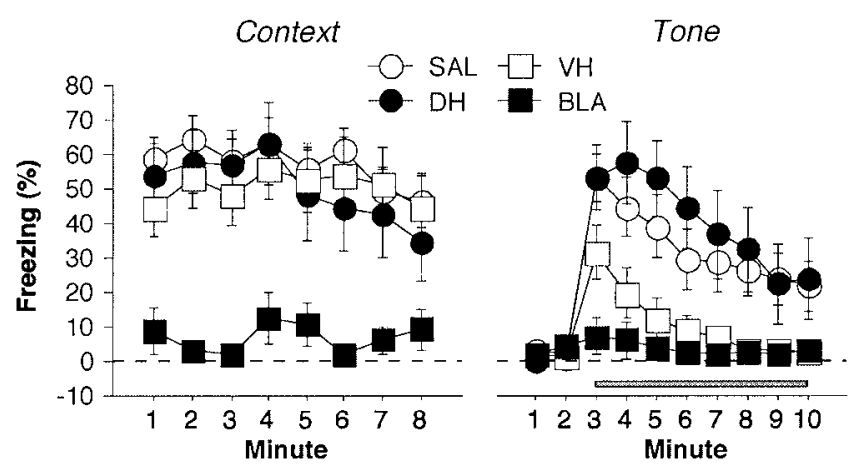

Figure 5. Effects of pretraining muscimol infusions into the dorsal hippocampus $(\mathrm{DH})$, ventral hippocampus $(\mathrm{VH})$, or basolateral complex of the amygdala (BLA) on the acquisition of conditional freezing in Experiment 1. Context: Mean $( \pm S E M)$ percentage of freezing during the 8-min context extinction test conducted 1 day after fear conditioning in rats that received intracranial muscimol infusions into the $\mathrm{DH}, \mathrm{VH}$, or BLA; control rats receiving saline (SAL) infusions into these brain areas were collapsed into a single group. Tone: Mean $( \pm S E M)$ percentage of freezing during the 8-min tone extinction test conducted 2 days after fear conditioning in rats that received intracranial muscimol infusions into the $\mathrm{DH}, \mathrm{VH}$, or BLA; control rats receiving saline (SAL) infusions into these brain areas were collapsed into a single group. Tone onset occurred at the start of the 3rd min of the test and remained on during the remainder of the test (gray bar). 
infusions did not affect tone freezing in the earliest part of the tone extinction test. This suggests that some learning occurred in these rats, despite their deficit later in the extinction test. Nonetheless, it is clear that $\mathrm{VH}$ muscimol infusions prior to fear conditioning yield a selective deficit in the acquisition of auditory fear conditioning when the entire extinction test is considered.

The basis for the auditory fear-conditioning deficit in rats receiving intra- $\mathrm{VH}$ muscimol is unclear, although there are several possibilities. First, VH muscimol infusions may produce a sensory deficit in processing the CS or the US or an associative deficit in learning the relationship between these stimuli. It is not likely that $\mathrm{VH}$ muscimol infusions yielded a US processing deficit insofar as conditional freezing to the conditioning context was normal. Nor is it likely that VH muscimol infusions produced a general sensory or perceptual impairment that affected processing of the contextual and auditory CSs. However, it is possible that $\mathrm{VH}$ muscimol infusions yielded a specific deficit in processing the acoustic CS. The proximity of the $\mathrm{VH}$ infusion sites to the auditory thalamus is consistent with this view. Indeed, a recent report (Edeline et al., 2002) suggested that intracranial muscimol infusions may yield a broader radius of neural inactivation than previously measured (Martin, 1991). Given these new estimates of muscimol spread, it is possible that the effects of $\mathrm{VH}$ muscimol on auditory fear conditioning in Experiment 1 were mediated by muscimol diffusion to the adjacent auditory thalamus. That is, muscimol may have inactivated auditory thalamic neurons, thereby preventing the transmission of auditory information to brain structures in the forebrain (e.g., the amygdala) responsible for elaborating CS-US associations. Experiment 2 addresses this possibility.

\section{Experiment 2}

Experiment 1 reveals a selective role for the $\mathrm{VH}$ in the acquisition of auditory compared with contextual fear conditioning. The aim of Experiment 2 was to compare the effects of pretesting muscimol infusions into the $\mathrm{DH}$ or $\mathrm{VH}$ on the expression of Pavlovian fear conditioning. If $\mathrm{VH}$ muscimol infusions affect processing of auditory CSs, then a deficit in the expression of freezing to an auditory $\mathrm{CS}$ is expected in rats receiving intra- $\mathrm{VH}$ muscimol prior to extinction testing. Rats were infused with muscimol or vehicle into the $\mathrm{DH}$ or $\mathrm{VH}$ shortly before the context and tone retention tests conducted 24 and $48 \mathrm{hr}$ following conditioning, respectively. Rats with cannulas aimed at the BLA served as a comparison group demonstrating the deleterious effects of muscimol on the expression of contextual and auditory fear conditioning (Helmstetter \& Bellgowan, 1994; Muller et al., 1997). As in Experiment 1, freezing served as the measure of fear.

\section{Method}

Subjects and design. Fifty-two rats received surgical implantation of stainless steel cannulas aimed at the DH, VH, and BLA as described in Experiment 1. Rats in each group were randomly assigned to receive intracranial infusions of muscimol or the saline vehicle solution $20 \mathrm{~min}$ before fear testing (i.e., pretesting infusions). Eight subjects were excluded because of inaccurate cannula placements. The vehicle animals for each anatomical placement (DH and $\mathrm{VH}$; there were no animals with BLA placements that received vehicle) were collapsed to form one control group because there were no significant differences between the groups during either training, $F(1,7)=0.34$, or extinction testing: context, $F(1,7)=$
2.52; tone, $F(1,7)=0.91$. This yielded the following groups: VEH $(n=$ $9)$, DH $(n=15), \mathrm{VH}(n=15)$, and BLA $(n=5)$.

Surgery and procedures. All of the methods were identical to those in Experiment 1 except that all of the animals were conditioned drug-free, and the intracranial infusions were performed before the context and tone extinction tests.

\section{Results and Discussion}

Histology. Cannula placements are illustrated in Figure 6. They were similar to those reported for Experiment 1 (see Figures 1 and 2). The cannula placements were bilaterally symmetrical and clustered in the targeted brain areas. Placements in the DH were centered on hippocampal area CA1 and the dentate gyrus; placements in the $\mathrm{VH}$ were centered on the caudal dentate gyrus, CA3,

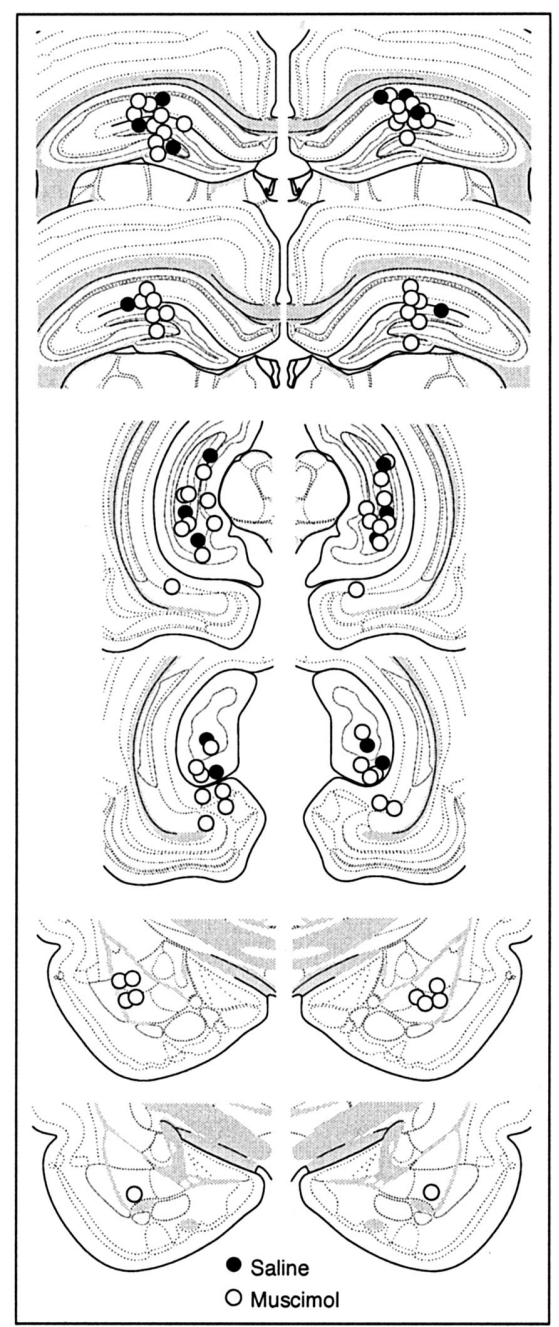

Figure 6. Schematic representation of cannula placements in the dorsal hippocampus (top), ventral hippocampus (middle), and basolateral complex of the amygdala (bottom) for Experiment 2. For each brain area, rats were infused with either saline or muscimol. Coronal brain section images were reprinted from Brain Maps: Structure of the Rat Brain, 2nd ed., L. W. Swanson, Levels 28, 29, 31, 32, 39, and 40, Copyright 1998, with permission from Elsevier. 
and ventral subiculum; and placements in the BLA were centered on the lateral and basolateral nuclei of the amygdala.

Behavior. Freezing during the fear conditioning session is shown in Figure 7. Group labels refer to the treatments administered before extinction testing; all animals were drug-free during the conditioning session. Compared with the 3-min preshock period (Pre), footshock reliably increased freezing in all of the groups across all of the 1-min postshock intervals following each conditioning trial: main effect of trial, $F(5,200)=20.9, p<.0001$. There were no differences between the groups in the total level of freezing during the conditioning session-nonsignificant main effect of group, $F(3,40)=0.69-$ or in the pattern of freezing across training trials: nonsignificant Group $\times$ Trial interaction, $F(15$, $200)=0.54$. The similar levels of freezing in the groups is not surprising insofar as all animals were drug-free during this phase of training.

Conditional freezing during the context and tone extinction tests, respectively, is shown in Figure 8. As in Experiment 1, infusions of muscimol into the BLA produced severe deficits in conditional freezing during both the context and tone extinction tests. However, unlike Experiment 1, hippocampal muscimol infusions did not impair the expression of freezing behavior during either the context or tone test. These impressions were confirmed with one-way ANOVAs performed on the context and tone freezing data averaged across the 8-min tests: context, $F(3,40)=3.01$, $p<.05$; tone, $F(3,40)=2.97, p<.05$. Post hoc comparisons $(p<.05)$ performed on both the context and tone freezing means confirmed that rats in the BLA group differed significantly from rats in all other groups, which did not differ from one another. In contrast to the elevations in preshock freezing found in Experiment 1 , pretone freezing during the tone extinction test was not elevated by muscimol infusions, $F(3,40)=0.70$. We have previously reported that DH muscimol infusions augment the expression of contextual freezing (Holt \& Maren, 1999). It is not clear why

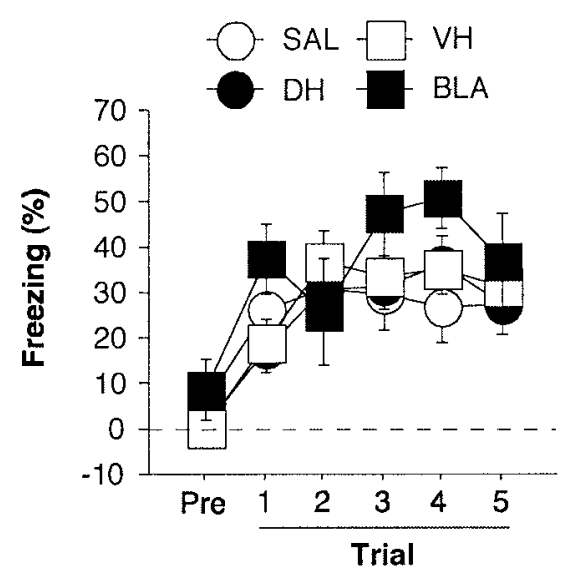

Figure 7. Effects of pretraining muscimol infusions into the dorsal hippocampus $(\mathrm{DH})$, ventral hippocampus $(\mathrm{VH})$, or basolateral complex of the amygdala (BLA) on preshock (Pre) and immediate postshock freezing on the conditioning day in Experiment 2. Mean ( $\pm S E M$ ) percentage of freezing during the 3 -min preshock period and five 1-min postshock periods in rats that received intracranial muscimol infusions into the $\mathrm{DH}$, $\mathrm{VH}$, or BLA; control rats receiving saline (SAL) infusions into these brain areas were collapsed into a single group.

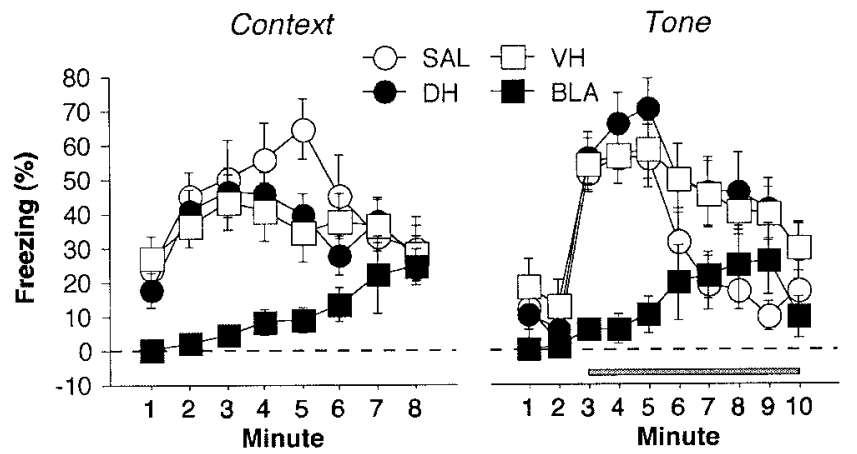

Figure 8. Effects of pretesting muscimol infusions into the dorsal hippocampus $(\mathrm{DH})$, ventral hippocampus $(\mathrm{VH})$, or basolateral complex of the amygdala (BLA) on the expression of conditional freezing in Experiment 2. Context: Mean $( \pm S E M)$ percentage of freezing during the 8-min context extinction test conducted 1 day after fear conditioning in rats receiving intracranial muscimol infusions into the $\mathrm{DH}, \mathrm{VH}$, or BLA; control rats receiving saline (SAL) infusions into these brain areas were collapsed into a single group. Tone: Mean $( \pm S E M)$ percentage of freezing during the 8 -min tone extinction test conducted 2 days after fear conditioning in rats receiving intracranial muscimol infusions into the $\mathrm{DH}, \mathrm{VH}$, or BLA; control rats receiving saline (SAL) infusions into these brain areas were collapsed into a single group. Tone onset occurred at the start of the 3rd min of the test and remained on during the remainder of the test (gray bar).

pretesting muscimol infusions did not augment contextual freezing in the present experiment.

These results reveal that $\mathrm{VH}$ muscimol infusions produce a robust deficit in the acquisition but not the expression of auditory fear conditioning. This suggests a selective role of the $\mathrm{VH}$ in associative processes governing the acquisition of auditory CS-US associations. Indeed, it is unlikely that VH muscimol infusions affect sensory processing of the auditory CS insofar as the expression of fear to an auditory CS was unaffected by $\mathrm{VH}$ muscimol. The precise role of the VH in encoding auditory CS-US associations is unknown and represents a fruitful area for further inquiry.

\section{Experiment 3}

It has been previously reported that extensive lesions of the ventral hippocampus and subiculum produce deficits in the acquisition of conditional freezing to both auditory and contextual stimuli (Maren, 1999b; Richmond et al., 1999). Therefore, we were surprised that VH muscimol infusions did not yield deficits in contextual freezing in Experiments 1 and 2. One possibility is that the experiments in the present study were run with fewer conditioning trials than those in our previous report, although there is reason to believe that this would render conditioning more dependent on the hippocampus (O'Reilly \& Rudy, 2001). Alternatively, the permanent lesions used in our previous report may have encompassed more brain tissue than the regions of pharmacological inactivation in the present study. To assess this possibility, we evaluated the influence of focal electrolytic lesions of the $\mathrm{VH}$ on the acquisition and expression of conditional freezing in Experiment 3. We used two lesion sites per hemisphere, compared with three sites per hemisphere in our previous study. Similar to our previous lesion work, we used 15 tone-footshock trials in the present experiment. 


\section{Method}

Subjects and design. Twenty-four rats received either sham surgery or electrolytic lesions of the VH 1 week prior to fear conditioning (VH-PRE, $n=8$; SH-PRE, $n=4$ ) or 1 day after fear conditioning (VH-POST, $n=$ 8 ; SH-POST, $n=4)$. The two sham groups did not differ from one another during either training, $F(1,6)=1.1$, or extinction testing-context, $F(1$, 6) $=0.78$; tone, $F(1,6)=1.62$ - and were collapsed into a single sham group for statistical analysis.

Surgery. One week before or 1 day after fear conditioning, the rats were treated with atropine methyl nitrate $(0.04-\mathrm{mg} / \mathrm{kg}$ body weight), anesthetized with an intraperitoneal injection of Nembutal (sodium pentobarbital, $65-\mathrm{mg} / \mathrm{kg}$ body weight), and mounted in a stereotaxic apparatus (David Kopf Instruments, Tujunga, CA). The scalp was incised and retracted, and head position was adjusted to place bregma and lambda in the same horizontal plane. Small burr holes (2-mm diameter) were drilled bilaterally in the skull for the placement of electrodes in the VH $(5.2 \mathrm{~mm}$ posterior to bregma, $5.0 \mathrm{~mm}$ lateral to the midline, $8.0 \mathrm{~mm}$ ventral to skull surface; $5.8 \mathrm{~mm}$ posterior to bregma, $5.0 \mathrm{~mm}$ lateral to the midline, $7.5 \mathrm{~mm}$ ventral to skull surface). Electrolytic lesions were made using an insulated electrode (except for $500-\mu \mathrm{m}$ at the tip), and anodal current (1 mA, $10 \mathrm{~s}$ ) was injected. Following surgery, the incision was closed with stainless steel wound clips, and the rats were allowed to recover on a heating pad before returning to their home cage.

Conditioning and testing procedures. All of the conditioning and testing procedures were identical to those in Experiment 1 except that the animals were given 15 , rather than 5 , conditioning trials. Furthermore, extinction testing occurred 1 week following fear conditioning to allow for surgical recovery in the SH-POST and VH-POST animals.

Lesion severity. To quantify the severity of the lesions, we used the rating scale reported in Maren (1999b). The extent of damage to the ventral subiculum, medial entorhinal cortex, ventral CA1, and caudal dentate gyrus and CA3 was rated and assigned a numeric score. For each brain region, scores of 4,2 , or 1 were assigned for severe, moderate, or minimal damage, respectively; and a score of 0 was assigned if there was no damage observed. Severe damage involved complete or near complete lesions (approximately 100\%), moderate damage involved substantial but not complete lesions (approximately 50\%), and minimal damage involved limited lesions (approximately $25 \%$ or less).

\section{Results and Discussion}

Histology. High-resolution scans of thionin-stained sections from a representative rat with an electrolytic VH lesion are shown in Figure 9. A schematic representation of the maximal and minimal extent of the $\mathrm{VH}$ lesions in all of the rats is shown in Figure 10. As shown, there was extensive damage to the ventral subiculum and the caudal pole of the hippocampal formation including the dentate gyrus, hippocampal area CA1, and hippocampal area CA3. Lesion severity scores are reported in Table 1. As in Maren (1999b), the most severe damage was localized to the ventral subiculum, with more limited damage to the medial entorhinal cortex, ventral CA1, and ventral dentate gyrus and CA3. There were no differences between rats in the VH-PRE and VHPOST groups in lesion severity for any of the brain areas (MannWhitney $U, p s>.15)$. These lesions were smaller than the neurotoxic lesions reported in our previous study (Maren, 1999b), and they resulted in comparatively less damage to the dentate gyrus, hippocampal area CA1, and hippocampal area CA3.

Behavior. We previously reported that $\mathrm{VH}$ lesions produce significant increases in per-shock locomotor activity (Maren, 1999b). It was therefore of interest to determine whether the focal VH lesions used in the present study produced a similar increase in

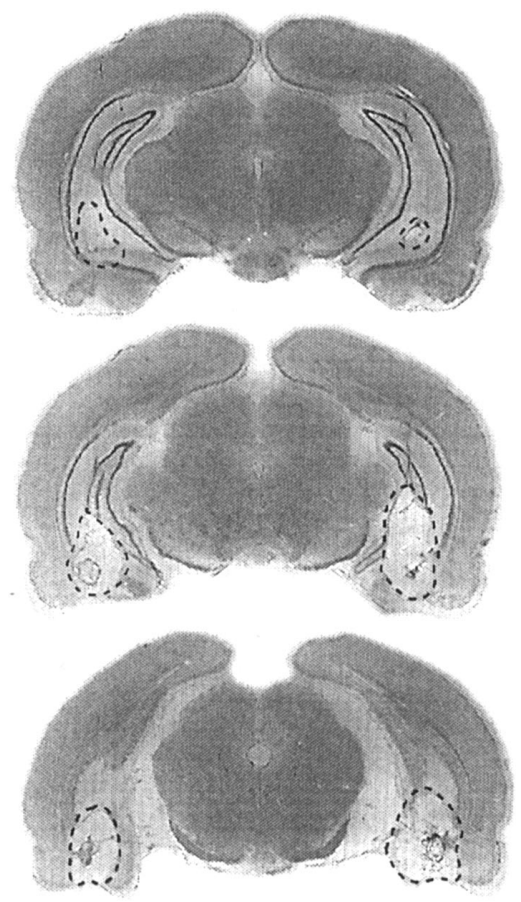

Figure 9. High-resolution scans of thionin-stained coronal sections from a representative rat with an electrolytic lesion of the ventral hippocampus. The lesion produced severe damage in the ventral subiculum, moderate damage in the ventral dentate gyrus and hippocampal area CA1 and CA3, and minimal damage to the medial entorhinal cortex.

locomotor activity. As in Experiment 1, we quantified activity in the 3-min preshock period on the conditioning day. We found no differences in motor activity between naive rats (rats that were scheduled to receive surgery after training), SH rats, and rats with pretraining VH lesions, $F(1,22)=0.47$, data not shown. Thus, unlike the larger lesions reported in Maren (1999b), the lesions used in the present study did not affect baseline motor activity.

Freezing during the fear conditioning session is shown in Figure 11. For the sake of clarity, postshock freezing following a subset of the trials is displayed (Trials $1,2,3,5,10$, and 15 are shown). Note that rats in the VH-POST group had not yet received VH lesions. Compared with the 3-min preshock period (Pre), footshock reliably increased freezing in all of the groups across all of the 1-min postshock intervals following each conditioning trial: main effect of trial, $F(6,126)=9.67, p<.0001$. There were no differences between the groups in the total level of freezing during the conditioning session-nonsignificant main effect of group, $F(2,21)=0.69-$ or in the pattern of freezing across training trials: nonsignificant Group $\times$ Trial interaction, $F(12,126)=$ 0.75. These results reveal that pretraining lesions of the $\mathrm{VH}$ do not affect immediate postshock freezing.

Conditional freezing during the context and tone extinction tests, respectively, is shown in Figure 12. Similar to Experiments 1 and 2, electrolytic VH lesions produced a selective deficit in auditory fear conditioning when made prior to fear conditioning (VH-PRE). It is interesting to note that posttraining VH lesions produced a deficit in freezing to not only the auditory CS but that they also generated an impairment in freezing to the conditioning 


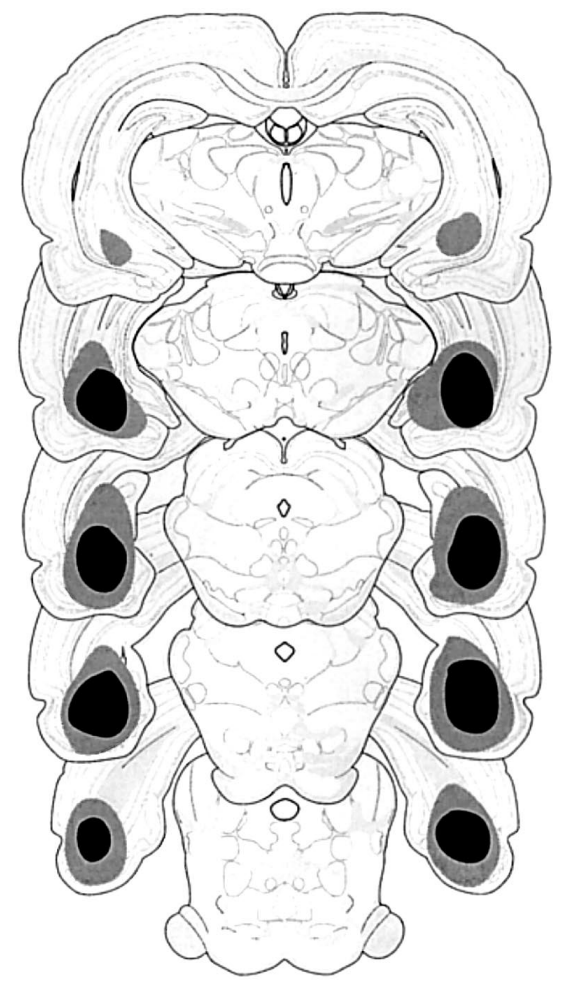

Figure 10. Schematic representation of the extent of the ventral hippocampus lesions in Experiment 3 (maximum lesion, gray; minimum lesion, black). Coronal brain section images reprinted from Brain Maps: Structure of the Rat Brain, 2nd ed., L. W. Swanson, Plates 36, 38, 40, 42, and 44, Copyright 1998, with permission from Elsevier.

context. These impressions were confirmed by one-way ANOVAs performed on the context and tone freezing data averaged across the respective extinction tests. The ANOVAs revealed significant main effects of group for both context, $F(2,21)=22.3, p<.0001$, and tone, $F(2,21)=4.2, p<.05$, freezing. Post hoc comparisons $(p<.05)$ revealed that VH-POST rats exhibited significantly lower freezing during the context extinction test than the $\mathrm{SH}$ and VH-PRE groups, which did not differ from one another. Moreover, both the VH-PRE and VH-POST groups exhibited impaired freezing during the tone extinction test relative to the $\mathrm{SH}$ control but did

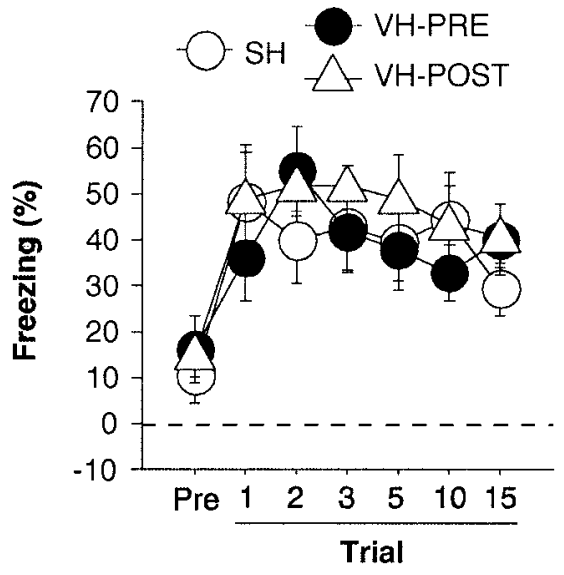

Figure 11. Effects of pretraining lesions of the ventral hippocampus $(\mathrm{VH})$ on preshock (Pre) and immediate postshock freezing on the conditioning day in Experiment 3. Mean $( \pm S E M)$ percentage of freezing during the 3-min preshock period and five 1-min postshock periods in rats that received pretraining $\mathrm{VH}$ lesions (VH-PRE) or sham surgery $(\mathrm{SH})$; also shown are rats designated to receive $\mathrm{VH}$ lesions after the fear conditioning session (VH-POST)

not differ from one another. As with muscimol infusions, $\mathrm{VH}$ lesions did not affect conditional freezing to the tone CS during the early part of the tone extinction test. An analysis of the first $30 \mathrm{~s}$ on the extinction test revealed no significant group effect, $F(2$, $21)=3.0$. This suggests that some learning occurred in rats with VH lesions, despite their deficit later in the extinction test.

These results extend Experiments 1 and 2 and reveal that pretraining lesions of the $\mathrm{VH}$ reproduce the effects of pretraining muscimol infusions on the acquisition of auditory fear conditioning. However, they also reveal an important dissociation in the effects of reversible and permanent lesions of the $\mathrm{VH}$ on the expression of fear conditioning memories. Whereas muscimol infusions had no effect on the expression of contextual fear, permanent lesions had effects on the expression of both auditory and contextual fear. As we have argued previously (Maren, 1999b; Maren et al., 1998), it is unlikely that this represents a performance deficit brought on by locomotor hyperactivity. Indeed, rats with $\mathrm{VH}$ lesions made prior to conditioning exhibited robust levels of contextual freezing that was no different from that in controls. Moreover, they did not exhibit increased motor activity prior to

Table 1

Mean Ratings (Interquartile Range) of Lesion Severity in Rats With Ventral Hippocampal Lesions

\begin{tabular}{llcccr}
\hline & & \multicolumn{4}{c}{ Brain region } \\
\cline { 3 - 6 } Group & $n$ & vSUB & mEC & vCA1 & DG/CA3 \\
\hline VH-PRE & 8 & $3.25(2.00)$ & $1.38(1.00)$ & $1.38(1.00)$ & $1.50(1.00)$ \\
VH-POST & 8 & $3.50(2.00)$ & $1.50(1.00)$ & $1.75(0.50)$ & $1.75(0.50)$ \\
\hline
\end{tabular}

Note. Maximum score $=4$; severe damage $(\sim 100 \%)=4$; moderate damage $(\sim 50 \%)=2$; minimal damage $(\sim 25 \%$ or less $)=1$; no damage $=0$. vSUB $=$ ventral subiculum; $\mathrm{mEC}=$ medial entorhinal cortex; $\mathrm{vCA} 1=$ ventral hippocampal area CA1; DG/CA3 = caudal dentate gyrus and hippocampal area CA3; VH-PRE = rats that received ventral hippocampus lesions before training; $\mathrm{VH}-\mathrm{POST}=$ rats that received ventral hippocampus lesions after fear conditioning. 


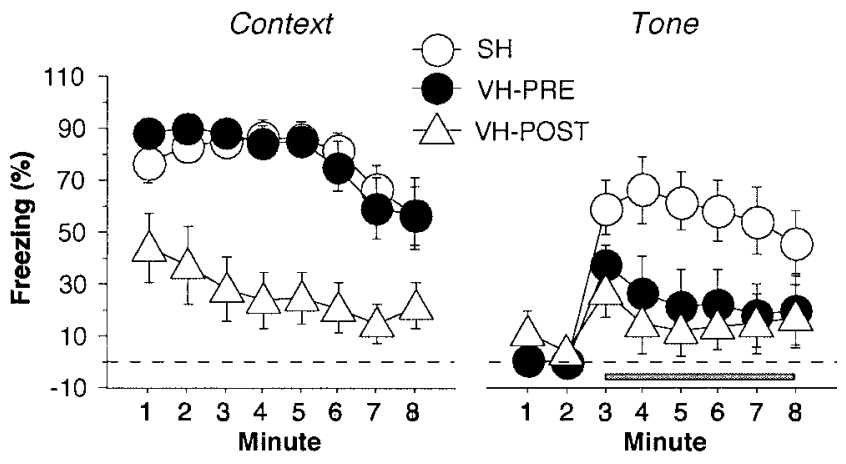

Figure 12. Effects of pre- or posttraining lesions of the ventral hippocampus $(\mathrm{VH})$ on the acquisition and expression of conditional freezing in Experiment 3. Context: Mean $( \pm S E M)$ percentage of freezing during the 8-min context extinction test conducted 1 day after fear conditioning in rats receiving either pretraining lesions of the VH (VH-PRE) or posttraining lesions of the VH (VH-POST); rats receiving pre- or posttraining sham surgery $(\mathrm{SH})$ were collapsed into a single group. Tone: Mean ( \pm SEM) percentage of freezing during the 8-min tone extinction test conducted 2 days after fear conditioning in rats receiving either pretraining of the $\mathrm{VH}$ (VH-PRE) or posttraining lesions of the VH (VH-POST); rats receiving pre- or posttraining sham surgery were collapsed into a single group (SH). Tone onset occurred at the start of the $3 \mathrm{rd}$ min of the test and remained on during the remainder of the test (gray bar).

footshock on the training day. An alternative possibility is that electrolytic lesions produce a broader region of disruption than muscimol infusions and that a substantial volume of hippocampal tissue (whether in the $\mathrm{DH}$ or $\mathrm{VH}$ ) must be disrupted in order to observe deficits in the expression of contextual fear. This would accord with our failure to disrupt contextual freezing with intrahippocampal muscimol and the relationship between the magnitude of hippocampal damage and the extent of retrograde amnesia for context fear (Anagnostaras et al., 2001).

\section{General Discussion}

The present report reveals an important functional dissociation between the dorsal and ventral hippocampus in the acquisition of Pavlovian fear conditioning in rats. Activation of $\mathrm{GABA}_{\mathrm{A}}$ receptors with muscimol or permanent lesions in the $\mathrm{VH}$ produced a robust and selective impairment in the acquisition of auditory fear conditioning, indexed by conditional freezing behavior. In contrast, muscimol infusions into the $\mathrm{DH}$ did not affect the acquisition of auditory fear conditioning, despite marginally increasing unconditioned freezing before conditioning. Of importance, the acquisition of contextual fear conditioning was not affected by infusions of muscimol into either $\mathrm{DH}$ or $\mathrm{VH}$. This does not represent a differential sensitivity of auditory and contextual fear conditioning to $\mathrm{GABA}_{\mathrm{A}}$ agonists in general, insofar as muscimol infusions into the BLA abolished the acquisition and expression of both contextual and auditory fear conditioning. Hence, the present study reveals a more selective involvement of the ventral hippocampus in auditory fear conditioning than previously reported. It is surprising that our results suggest that GABAergic synaptic transmission in the hippocampus is only involved in the acquisition of conditional fear to a discrete auditory CS and is not involved in the expression of either contextual or auditory freezing.

\section{Anatomical Basis for Fear Conditioning Deficits After Intrahippocampal Muscimol Infusions}

We have argued that the effect of dorsal and ventral hippocampal muscimol infusions on auditory fear conditioning is a consequence of different regions along the longitudinal axis of the hippocampus coming under the influence of the drug in the two cases. However, it is possible that different hippocampal subfields are affected by muscimol when infused into the DH or VH. That is, in Experiments 1 and 2, DH placements were centered on hippocampal area CA1 and the dentate gyrus, whereas VH placements were centered on hippocampal area CA3 and the dentate gyrus. If only hippocampal area CA3 were involved in auditory fear conditioning, then $\mathrm{VH}$, but not $\mathrm{DH}$, muscimol infusions might be expected to affect the acquisition of conditional freezing to an auditory CS.

This scenario presumes that the radius of muscimol inactivation is rather restricted to the vicinity of the cannula tip. A recent study challenges this notion (Edeline et al., 2002) and suggests that the extent of muscimol inactivation produced by the infusions in the present study would be sufficient to affect all hippocampal subfields (CA1, CA3, and dentate gyrus) from 1-3 $\mathrm{mm}$ beyond the cannula tip within either the dorsal or ventral half of the hippocampus. Thus, the relative inactivation of the dorsal versus ventral hippocampus is likely to be a more important dimension than the relative inactivation of various hippocampal subfields within the $\mathrm{DH}$ and $\mathrm{VH}$ in determining the consequences of muscimol inactivation in the present study.

In fact, the pattern of results we have obtained using muscimol infusions into the hippocampus is largely consistent with the neurotoxic lesion literature. That is, neurotoxic lesions of the DH prior to training do not impair contextual freezing (Cho et al., 1999; Frankland et al., 1998; Maren et al., 1997; Richmond et al., 1999; cf. Young et al., 1994) and typically do not affect freezing to auditory conditional stimuli (Cho et al., 1999; Richmond et al., 1999; but see Maren et al., 1997). Furthermore, pretraining VH lesions tend to produce robust deficits in the acquisition of auditory fear conditioning and only modest deficits in the acquisition of contextual freezing (Bannerman et al., 2003; Kjelstrup et al., 2002; Maren, 1999b; Maren \& Fanselow, 1995; Richmond et al., 1999; Tuvnes, Steffenach, Murison, Moser, \& Moser, 2003). In addition, as shown in Experiment 3, pretraining electrolytic lesions of the $\mathrm{VH}$ mirror the effects of pretraining intra- $\mathrm{VH}$ muscimol infusions and produce a selective deficit in the acquisition of auditory fear conditioning.

However, as reported before, intrahippocampal muscimol infusions did not affect the expression of either contextual or auditory fear conditioning (Corcoran \& Maren, 2001; Holt \& Maren, 1999). The failure of either $\mathrm{DH}$ or $\mathrm{VH}$ muscimol to affect the expression of conditional freezing stands in stark contrast to the effects of lesions of these structures on conditional freezing. That is, electrolytic or neurotoxic lesions of either the $\mathrm{DH}$ or $\mathrm{VH}$ produce profound impairments in contextual freezing (Antoniadis \& McDonald, 2001; Kim \& Fanselow, 1992; Kim et al., 1993; Maren, 1999b; Maren et al., 1997; Maren \& Fanselow, 1997; McNish et al., 2000; Phillips \& LeDoux, 1992; Richmond et al., 1999), and 
the expression of fear to an auditory CS is severely attenuated by posttraining VH lesions (Experiment 3; Maren, 1999b).

One account of these results is that permanent lesions disrupt more tissue in the target brain structure than intracranial drug infusions. Metabolic mapping studies are underway to address this possibility. An alternative is that lesion procedures produce transsynaptic depolarization that damages neural systems interconnected with the brain structure targeted by the infusion. There is some support for this possibility (Anagnostaras et al., 2001). In any case, substantial work is necessary to understand the functional differences between permanent and reversible brain lesions. While both manipulations produce neuronal dysfunction, it is clear that the nature, localization, and time course of this dysfunction are distinct.

\section{Pharmacological Basis for Fear Conditioning Deficits After Intrahippocampal Muscimol Infusions}

Although intrahippocampal muscimol infusions reproduce some of the effects of neurotoxic lesions on the acquisition of fear conditioning, it is noteworthy that they do not mimic the effects of other pharmacological agents. For example, it has been reported that intra-DH infusions of scopolamine (a muscarinic cholinergic receptor antagonist; Gale, Anagnostaras, \& Fanselow, 2001; Wallenstein \& Vago, 2001), 2-amino-5-phosphonovalerate (APV, an NMDA receptor antagonist; Stiedl, Birkenfeld, Palve, \& Spiess, 2000; Young et al., 1994), or (R, S)-alpha-methyl-4carboxyphenylglycine (MCPG, a metabotropic glutamate receptor antagonist; Frohardt, Guarraci, \& Young, 1999) produce selective deficits in the acquisition of contextual fear conditioning. These data suggest that GABAergic synapses in the DH may play a different role in the acquisition of fear conditioning than cholinergic or glutamatergic synapses. Intra- $\mathrm{VH}$ infusions of either muscimol or the NMDA receptor antagonist MK-801 have been reported to impair the acquisition of contextual fear conditioning (Bast et al., 2001b; Zhang et al., 2001), although we have found intact contextual fear conditioning after VH muscimol infusions. Collectively, it appears that glutamatergic and cholinergic agents have more potent effects on fear conditioning than do GABAergic drugs.

Nonetheless, it is difficult to account for the fact that intra-DH infusions of scopolamine, APV, and MCPG affect the acquisition of contextual fear conditioning, whereas intra-DH muscimol infusions do not. This is particularly perplexing in view of the fact that muscimol infusions into the $\mathrm{VH}$ produce substantial deficits in auditory fear conditioning. Insofar as muscimol infusions yield an inactivation of neuronal tissue that is functionally equivalent to a permanent lesion (Edeline et al., 2002; Martin, 1991), one is left concluding that DH lesions (whether by conventional or reversible methods) are less deleterious to contextual conditioning than disrupting cholinergic or glutamatergic neurotransmission within the DH.

One possible explanation for spared contextual fear conditioning after DH muscimol infusions is that the VH mediates contextual fear conditioning after permanent or reversible lesions of the DH (alternatively, as discussed below, rats adopt different strategies after DH inactivation). Indeed, it has recently been reported that spatial learning in the Morris water maze is only impaired by intrahippocampal muscimol infusions at two sites within the hip- pocampus; single site infusions like the ones used in the present study were ineffective (Tuvnes et al., 2003). Moreover, the DH and $\mathrm{VH}$ both appear to be capable of mediating spatial learning under some conditions (de Hoz, Knox, \& Morris, 2003). Accordingly, muscimol infusions that target the entire hippocampus might prevent the acquisition of contextual fear conditioning. Of course, one has to assume that $\mathrm{VH}$ compensation after $\mathrm{DH}$ lesions or muscimol either does not occur after infusion of scopolamine, APV, or MCPG into the DH or that these latter manipulations come to influence a larger hippocampal area (including both $\mathrm{DH}$ and $\mathrm{VH}$ ) than the muscimol infusions we have used in the present study.

\section{Psychological Basis for Auditory Fear Conditioning Deficits After Intrahippocampal Muscimol Infusions}

The failure of muscimol inactivation of the DH to impair contextual fear conditioning is a surprise in light of the widespread view that the $\mathrm{DH}$ makes a special contribution to the encoding of contextual representations that are necessary for contextual fear conditioning (Fanselow, 2000; O'Reilly \& Rudy, 2001). One possibility discussed above is that the VH mediates contextual fear conditioning in the absence of the DH. Alternatively, as we and others have previously argued, there are at least two types of representations that can support contextual conditioning: a hippocampal-dependent conjunctive (configural) representation and a hippocampal-independent elemental representation (Maren, 2001; Maren et al., 1997; Rudy et al., 2002). Under the conditions used in the present study, it is possible that animals use an elemental (nonhippocampal) strategy to condition fear to the training context when the DH is inactive. In fact, recent data from Rudy and colleagues (Jerry Rudy, personal communication, April 4, 2003) reveal that infusion of muscimol into the DH only impairs contextual fear conditioning when animals must retrieve a conjunctive representation of context established in a shock-free preexposure session. Hence, the fear conditioning procedure, particularly the placement-to-shock interval, could be an important determinant of hippocampal involvement in context conditioning (Wiltgen, Sanders, Behne, \& Fanselow, 2001).

Of course, it is difficult to argue that elemental strategies are entirely independent of the hippocampus in the light of the present data showing a robust effect of intra- $\mathrm{VH}$ muscimol on the acquisition of auditory fear conditioning. What accounts for the role of the $\mathrm{VH}$ in conditioning to auditory stimuli? One possibility is that infusion of muscimol into the $\mathrm{VH}$ affected nearby brain structures, such as the auditory thalamus, that are involved in relaying auditory information to the auditory cortex and amygdala. However, we discount this possibility because pretesting infusion of muscimol into the $\mathrm{VH}$ had no effect on the expression of fear to an auditory CS (Experiment 2). Another possibility is that VH muscimol infusions do not affect auditory fear condition per se but affect the ability of the CS-US association encoded during training to generalize to the continuous CS during the extinction test. Consistent with this possibility, freezing during the earliest part of the extinction test (i.e., the first $30 \mathrm{~s}$ of the tone) was not affected by VH lesions. This suggests that some learning about the CS-US relationship had occurred in these animals. It is possible that in these animals, the association is encoded in a manner that does not promote generalization to CSs of different (in this case, longer) 
durations. It will be important to address whether an extinction procedure that matches the training and testing CS durations produces an equivalent pattern of results.

The pattern of conditional freezing exhibited by VH rats during the tone extinction test may simply be representative of a weak CS-US association encoded by these animals, rather than a generalization deficit. One point that argues against this possibility is that the same pattern of freezing deficits was observed after both 5 and 15 conditioning trials in rats trained after $\mathrm{VH}$ disruption (muscimol in Experiment 1 and electrolytic lesions in Experiment 3). That is, tripling the number of conditioning trials did not substantially alter the nature of the deficit in rats with $\mathrm{VH}$ lesions, although the permanent lesions in Experiment 3 may have counteracted the effects of additional training that may have benefited animals receiving intra-VH muscimol. It remains to be determined if overtraining would overcome the deleterious effects of muscimol inactivation of the $\mathrm{VH}$ on fear conditioning, as it does after BLA lesions, for example (Maren, 1999a).

A role for the $\mathrm{VH}$ in auditory conditioning is consistent with a recent report from Feldon and colleagues who found that either tetrodotoxin or NMDA infusions into the VH affected the acquisition of auditory fear conditioning (Bast et al., 2001b; Zhang et al., 2001). They also reported a nonsignificant impairment in auditory fear conditioning after muscimol infusions into the VH. It is interesting to note, however, that they have found that tetrodotoxin, NMDA, and muscimol infusions into the $\mathrm{VH}$ impair the acquisition of context conditioning. In contrast, we have not observed impairments in the acquisition of contextual fear conditioning after infusions of muscimol into the VH (Experiment 1). One possible reason for this discrepancy is that the average levels of contextual freezing in their study were quite low ( $\sim 30 \%$ freezing). It may be that weak contextual memories are more sensitive to hippocampal manipulations than are strong contextual memories.

\section{Function of the DH and VH: Continuous or Nodal?}

An important question raised by this and other studies is whether the hippocampus is functionally segregated into dorsal and ventral nodes that perform different neural computations and processes or whether the $\mathrm{DH}$ and $\mathrm{VH}$ represent a continuum of common function along the longitudinal axis of the hippocampus. It is not surprising that the available evidence supports both ideas. Several studies suggest that the $\mathrm{DH}$ and $\mathrm{VH}$ perform different behavioral functions (Hock \& Bunsey, 1998; M. B. Moser \& Moser, 1998b; Nadel, 1968), although the functional distinction between the DH and VH is less clear in other studies (de Hoz et al., 2003; Ferbinteanu \& McDonald, 2000).

Consistent with the former hypothesis, several investigators have shown that the acquisition of spatial information requires the dorsal, but not ventral, hippocampus (Bannerman et al., 2002, 2003; Bannerman et al., 1999; Kjelstrup et al., 2002; E. Moser, Moser, \& Andersen, 1993; M. B. Moser \& Moser, 1998a). In addition, recent data have emerged implicating a dissociable role for the $\mathrm{DH}$ and $\mathrm{VH}$ in unconditioned anxiety. Ventral hippocampus, but not dorsal hippocampus, lesions impair food neophobia and emergence behavior (Bannerman et al., 2002, 2003). Similarly, Moser and colleagues have recently shown that $\mathrm{VH}$, but not $\mathrm{DH}$, lesions affect glucocorticoid responses to bright light and elevated plus maze, without affecting the acquisition of contextual fear conditioning (Kjelstrup et al., 2002). In the present study, we provide evidence that auditory fear conditioning is disrupted by $\mathrm{VH}$, but not $\mathrm{DH}$, inactivation. The dissociable contributions of the VH and DH spatial learning, unconditioned anxiety, and auditory fear conditioning may be related to the distinct anatomical connectivity of the two areas. Whereas the DH is strongly interconnected with cortical structures and the septum (Risold \& Swanson, 1996), the VH and ventral subiculum are uniquely interconnected with the amygdala and hypothalamus (Canteras \& Swanson, 1992).

Other evidence, however, blurs the distinction between the DH and $\mathrm{VH}$ and suggests the two brain areas may represent a continuum of function along the longitudinal axis of the hippocampus. For example, recent data suggest that both the $\mathrm{DH}$ and $\mathrm{VH}$ can acquire spatial memories in the Morris water maze and that training parameters play an important role in revealing spared function in animals with either DH or VH lesions (de Hoz et al., 2003). Moreover, $\mathrm{DH}$ or $\mathrm{VH}$ lesions produce similar deficits in the acquisition of place preferences after discriminative contextual fear conditioning (Ferbinteanu \& McDonald, 2000); we have shown that neurotoxic lesions of the DH (Maren et al., 1997) or VH (Experiment 3; Maren, 1999b) made after fear conditioning produce deficits in conditional freezing to both contextual and auditory stimuli. These data encourage the view that there is substantial functional overlap between the dorsal and ventral hippocampus. Hence, rather than subserving unique behavioral and neural functions, the two regions may constitute a functional hippocampal continuum mediating learning and memory.

Consistent with both views, we have previously suggested a model whereby operations performed by the DH (formation of contextual representations) come to influence the amygdala, for example, via the VH (Maren \& Fanselow, 1995). By this view, the DH and VH serve specialized "nodal" functions that are integrated along the "continuous" longitudinal access of the hippocampus via axonal projections cascading from the dorsal to ventral pole of the hippocampus. In fear conditioning, we have proposed that the connectivity of the $\mathrm{VH}$ with the amygdala may be particularly important for allowing contextual representations formed in the DH to come into association with US representations in the amygdala (Maren, 2001). Thus, although the VH may or may not be involved in establishing contextual representations, it is required to convey these associations to the amygdala for association with shock. Consistent with our model, large lesions of the VH attenuate the acquisition and expression of contextual fear conditioning (Maren, 1999b; Maren \& Fanselow, 1995). Moreover, similar impairments in contextual fear conditioning are produced by either posttraining neurotoxic lesions in the DH or VH (Maren, 1999b; Maren et al., 1997) and pretraining infusions of NMDA receptor antagonists into the DH or VH (Bast, Zhang, \& Feldon, 2003; Zhang et al., 2001).

Of course, the results of the present experiments require that this model must be modified to incorporate the fact that $\mathrm{VH}$ lesions or inactivation produce robust impairments in auditory fear conditioning that are not produced by the same manipulations of the $\mathrm{DH}$ (or at least not to the same extent; Maren et al., 1997). Accordingly, contextual and spatial processing might be viewed as a continuous hippocampal function, operating along the dorsalventral extent of the hippocampus as has recently been proposed for spatial navigation (de Hoz et al., 2003; Ferbinteanu \& Mc- 
Donald, 2000). In contrast, discrete stimulus processing might be viewed as a nodal process requiring the VH, but not DH. Further studies are required to validate these distinctions in a variety of conditioning tasks and training parameters.

\section{References}

Anagnostaras, S. G., Gale, G. D., \& Fanselow, M. S. (2001). Hippocampus and contextual fear conditioning: Recent controversies and advances. Hippocampus, 11, 8-17.

Anagnostaras, S. G., Gale, G. D., \& Fanselow, M. S. (2002). The hippocampus and Pavlovian fear conditioning: Reply to Bast et al. Hippocampus, 12, 561-565.

Anagnostaras, S. G., Maren, S., \& Fanselow, M. S. (1999). Temporally graded retrograde amnesia of contextual fear after hippocampal damage in rats: Within-subjects examination. Journal of Neuroscience, 19, $1106-1114$.

Antoniadis, E. A., \& McDonald, R. J. (2001). Amygdala, hippocampus, and unconditioned fear. Experimental Brain Research, 138(2), 200-209.

Bannerman, D. M., Deacon, R. M. J., Offen, S., Friswell, J., Grubb, M., \& Rawlins, J. N. P. (2002). Double dissociation of function within the hippocampus: Spatial memory and hyponeophagia. Behavioral Neuroscience, 116, 884-901.

Bannerman, D. M., Grubb, M., Deacon, R. M. J., Yee, B. K., Feldon, J., \& Rawlins, J. N. P. (2003). Ventral hippocampal lesions affect anxiety but not spatial learning. Behavioural Brain Research, 139(1-2), 197-213.

Bannerman, D. M., Yee, B. K., Good, M. A., Heupel, M. J., Iversen, S. D., \& Rawlins, J. N. P. (1999). Double dissociation of function within the hippocampus: A comparison of dorsal, ventral, and complete hippocampal cytotoxic lesions. Behavioral Neuroscience, 113, 1170-1188.

Bast, T., Zhang, W. N., \& Feldon, J. (2001a). Hippocampus and classical fear conditioning. Hippocampus, 11, 828-831.

Bast, T., Zhang, W. N., \& Feldon, J. (2001b). The ventral hippocampus and fear conditioning in rats: Different anterograde amnesias of fear after tetrodotoxin inactivation and infusion of the $\operatorname{GABA}(\mathrm{A})$ agonist muscimol. Experimental Brain Research, 139(1), 39-52.

Bast, T., Zhang, W. N., \& Feldon, J. (2003). Dorsal hippocampus and classical fear conditioning to tone and context in rats: Effects of local NMDA-receptor blockade and stimulation. Hippocampus, 13, 657-675.

Canteras, N. S., \& Swanson, L. W. (1992). Projections of the ventral subiculum to the amygdala, septum, and hypothalamus: A PHAL anterograde tract-tracing study in the rat. Journal of Comparative Neurology, 324(2), 180-194.

Cho, Y. H., Friedman, E., \& Silva, A. J. (1999). Ibotenate lesions of the hippocampus impair spatial learning but not contextual fear conditioning in mice. Behavioural Brain Research, 98, 77-87.

Chun, M. M., \& Phelps, E. A. (1999). Memory deficits for implicit contextual information in amnesic subjects with hippocampal damage. Nature Neuroscience, 2, 844-847.

Corcoran, K. A., \& Maren, S. (2001). Hippocampal inactivation disrupts contextual retrieval of fear memory after extinction. Journal of Neuroscience, 21, 1720-1726.

de Hoz, L., Knox, J., \& Morris, R. G. M. (2003). Longitudinal axis of the hippocampus: Both septal and temporal poles of the hippocampus support water maze spatial learning depending on the training protocol. Hippocampus, 13, 587-603.

Douglas, R. J. (1967). The hippocampus and behavior. Psychological Bulletin, 67, 416-422.

Edeline, J. M., Hars, B., Hennevin, E., \& Cotillon, N. (2002). Muscimol diffusion after intracerebral microinjections: A reevaluation based on electrophysiological and autoradiographic quantifications. Neurobiology of Learning and Memory, 78(1), 100-124.

Eichenbaum, H. (1997). Declarative memory: Insights from cognitive neurobiology. Annual Review of Psychology, 48, 547-572.
Fanselow, M. S. (2000). Contextual fear, gestalt memories, and the hippocampus. Behavioural Brain Research, 110, 73-81.

Ferbinteanu, J., \& McDonald, R. J. (2000). Dorsal and ventral hippocampus: Same or different? Psychobiology, 28(3), 314-324.

Frankland, P. W., Cestari, V., Filipkowski, R. K., McDonald, R. J., \& Silva, A. J. (1998). The dorsal hippocampus is essential for context discrimination but not for contextual conditioning. Behavioral Neuroscience, 112, 863-874.

Frohardt, R. J., Guarraci, F. A., \& Young, S. L. (1999). Intrahippocampal infusions of a metabotropic glutamate receptor antagonist block the memory of context-specific but not tone-specific conditioned fear. Behavioral Neuroscience, 113, 222-227.

Gale, G. D., Anagnostaras, S. G., \& Fanselow, M. S. (2001). Cholinergic modulation of Pavlovian fear conditioning: Effects of intrahippocampal scopolamine infusion. Hippocampus, 11, 371-376.

Gewirtz, J. C., McNish, K. A., \& Davis, M. (2000). Is the hippocampus necessary for contextual fear conditioning? Behavioural Brain Research, 110, 83-95.

Gisquet-Verrier, P., Dutrieux, G., Richer, P., \& Doyere, V. (1999). Effects of lesions to the hippocampus on contextual fear: Evidence for a disruption of freezing and avoidance behavior but not context conditioning. Behavioral Neuroscience, 113, 507-522.

Helmstetter, F. J., \& Bellgowan, P. S. (1994). Effects of muscimol applied to the basolateral amygdala on acquisition and expression of contextual fear conditioning in rats. Behavioral Neuroscience, 108, 1005-1009.

Hock, B. J., \& Bunsey, M. D. (1998). Differential effects of dorsal and ventral hippocampal lesions. Journal of Neuroscience, 18, 7027-7032.

Holland, P. C., \& Bouton, M. E. (1999). Hippocampus and context in classical conditioning. Current Opinion in Neurobiology, 9(2), 195-202.

Holt, W., \& Maren, S. (1999). Muscimol inactivation of the dorsal hippocampus impairs contextual retrieval of fear memory. Journal of Neuroscience, 19, 9054-9062.

Honey, R. C., \& Good, M. (2000). Associative components of recognition memory. Current Opinion in Neurobiology, 10(2), 200-204.

Kim, J. J., \& Fanselow, M. S. (1992, May 1). Modality-specific retrograde amnesia of fear. Science, 256, 675-677.

Kim, J. J., Rison, R. A., \& Fanselow, M. S. (1993). Effects of amygdala, hippocampus, and periaqueductal gray lesions on short- and long-term contextual fear. Behavioral Neuroscience, 107, 1093-1098.

Kjelstrup, K. G., Tuvnes, F. A., Steffenach, H. A., Murison, R., Moser, E. I., \& Moser, M. B. (2002). Reduced fear expression after lesions of the ventral hippocampus. Proceedings of the National Academy of Sciences of the United States of America, 99, 10825-10830.

Maren, S. (1998). Overtraining does not mitigate contextual fear conditioning deficits produced by neurotoxic lesions of the basolateral amygdala. Journal of Neuroscience, 18, 3088-3097.

Maren, S. (1999a). Neurotoxic basolateral amygdala lesions impair learning and memory but not the performance of conditional fear in rats. Journal of Neuroscience, 19, 8696-8703.

Maren, S. (1999b). Neurotoxic or electrolytic lesions of the ventral subiculum produce deficits in the acquisition and expression of Pavlovian fear conditioning in rats. Behavioral Neuroscience, 113, 283-290.

Maren, S. (2001). Neurobiology of Pavlovian fear conditioning. Annual Review of Neuroscience, 24, 897-931.

Maren, S., Aharonov, G., \& Fanselow, M. S. (1996). Retrograde abolition of conditional fear after excitotoxic lesions in the basolateral amygdala of rats: Absence of a temporal gradient. Behavioral Neuroscience, 110, $718-726$.

Maren, S., Aharonov, G., \& Fanselow, M. S. (1997). Neurotoxic lesions of the dorsal hippocampus and Pavlovian fear conditioning in rats. Behavioural Brain Research, 88, 261-274.

Maren, S., Aharonov, G., Stote, D. L., \& Fanselow, M. S. (1996). $\mathrm{N}$-methyl-D-aspartate receptors in the basolateral amygdala are required 
for both acquisition and expression of conditional fear in rats. Behavioral Neuroscience, 110, 1365-1374.

Maren, S., Anagnostaras, S. G., \& Fanselow, M. S. (1998). The startled seahorse: Is the hippocampus necessary for contextual fear conditioning? Trends in Cognitive Sciences, 2, 39-42.

Maren, S., \& Fanselow, M. S. (1995). Synaptic plasticity in the basolateral amygdala induced by hippocampal formation stimulation in vivo. Journal of Neuroscience, 15, 7548-7564.

Maren, S., \& Fanselow, M. S. (1997). Electrolytic lesions of the fimbria/ fornix, dorsal hippocampus, or entorhinal cortex produce anterograde deficits in contextual fear conditioning in rats. Neurobiology of Learning and Memory, 67, 142-149.

Maren, S., \& Holt, W. (2000). The hippocampus and contextual memory retrieval in Pavlovian conditioning. Behavioural Brain Research, 110, 97-108.

Maren, S., Yap, S. A., \& Goosens, K. A. (2001). The amygdala is essential for the development of neuronal plasticity in the medial geniculate nucleus during auditory fear conditioning in rats. Journal of Neuroscience, 21, RC135.

Martin, J. H. (1991). Autoradiographic estimation of the extent of reversible inactivation produced by microinjection of lidocaine and muscimol in the rat. Neuroscience Letters, 127(2), 160-164.

McNish, K. A., Gewirtz, J. C., \& Davis, M. (1997). Evidence of contextual fear after lesions of the hippocampus: A disruption of freezing but not fear-potentiated startle. Journal of Neuroscience, 17, 9353-9360.

McNish, K. A., Gewirtz, J. C., \& Davis, M. (2000). Disruption of contextual freezing, but not contextual blocking of fear-potentiated startle, after lesions of the dorsal hippocampus. Behavioral Neuroscience, 114, $64-$ 76.

Morris, R. G., \& Frey, U. (1997). Hippocampal synaptic plasticity: Role in spatial learning or the automatic recording of attended experience? Philosophical Transactions of the Royal Society (London), Series B, 352, $1489-1503$.

Moser, E., Moser, M. B., \& Andersen, P. (1993). Spatial-learning impairment parallels the magnitude of dorsal hippocampal lesions, but is hardly present following ventral lesions. Journal of Neuroscience, 13, 39163925.

Moser, M. B., \& Moser, E. I. (1998a). Distributed encoding and retrieval of spatial memory in the hippocampus. Journal of Neuroscience, 18, $7535-7542$

Moser, M. B., \& Moser, E. I. (1998b). Functional differentiation in the hippocampus. Hippocampus, 8, 608-619.

Muller, J., Corodimas, K. P., Fridel, Z., \& LeDoux, J. E. (1997). Functional inactivation of the lateral and basal nuclei of the amygdala by muscimol infusion prevents fear conditioning to an explicit conditioned stimulus and to contextual stimuli. Behavioral Neuroscience, 111, 683-691.

Nadel, L. (1968). Dorsal and ventral hippocampal lesions and behavior. Physiology \& Behavior, 3, 891-900.

O'Keefe, J., \& Nadel, L. (1978). The hippocampus as a cognitive map. Oxford, England: Oxford University Press, Clarendon Press.

O'Reilly, R. C., \& Rudy, J. W. (2001). Conjunctive representations in learning and memory: Principles of cortical and hippocampal function. Psychological Review, 108, 311-345.

Phillips, R. G., \& LeDoux, J. E. (1992). Differential contribution of amygdala and hippocampus to cued and contextual fear conditioning. Behavioral Neuroscience, 106, 274-285.

Phillips, R. G., \& LeDoux, J. E. (1994). Lesions of the dorsal hippocampal formation interfere with background but not foreground contextual fear conditioning. Learning \& Memory, 1, 34-44.
Qin, Y. L., McNaughton, B. L., Skaggs, W. E., \& Barnes, C. A. (1997) Memory reprocessing in corticocortical and hippocampocortical neuronal ensembles. Philosophical Transactions of the Royal Society of London-Series B: Biological Sciences, 352(1360), 1525-1533.

Richmond, M. A., Yee, B. K., Pouzet, B., Veenman, L., Rawlins, J. N., Feldon, J., et al. (1999). Dissociating context and space within the hippocampus: Effects of complete, dorsal, and ventral excitotoxic hippocampal lesions on conditioned freezing and spatial learning. Behavioral Neuroscience, 113, 1189-1203.

Risold, P. Y., \& Swanson, L. W. (1996, June 7). Structural evidence for functional domains in the rat hippocampus. Science, 272, 1484-1486.

Rudy, J. W., Barrientos, R. M., \& O'Reilly, R. C. (2002). Hippocampal formation supports conditioning to memory of a context. Behavioral Neuroscience, 116, 530-538.

Rudy, J. W., \& O'Reilly, R. C. (1999). Contextual fear conditioning, conjunctive representations, pattern completion, and the hippocampus. Behavioral Neuroscience, 113, 867-880.

Sanders, M. J., Wiltgen, B. J., \& Fanselow, M. S. (2003). The place of the hippocampus in fear conditioning. European Journal of Pharmacology, 463(1-3), 217-223.

Selden, N. R., Everitt, B. J., Jarrard, L. E., \& Robbins, T. W. (1991). Complementary roles for the amygdala and hippocampus in aversive conditioning to explicit and contextual cues. Neuroscience, 42(2), 335350 .

Squire, L. R., \& Zola-Morgan, S. (1991, September 20). The medial temporal lobe memory system. Science, 253, 1380-1386.

Stiedl, O., Birkenfeld, K., Palve, M., \& Spiess, J. (2000). Impairment of conditioned contextual fear of C57BL/6J mice by intracerebral injections of the NMDA receptor antagonist APV. Behavioural Brain Research, 116, 157-168.

Swanson, L. W. (1998). Brain maps: Structure of the rat brain (2nd ed.). Amsterdam: Elsevier.

Tuvnes, F. A., Steffenach, H. A., Murison, R., Moser, M. B., \& Moser, E. I. (2003). Selective hippocampal lesions do not increase adrenocortical activity. Journal of Neuroscience, 23, 4345-4354.

Wallenstein, G. V., \& Vago, D. R. (2001). Intrahippocampal scopolamine impairs both acquisition and consolidation of contextual fear conditioning. Neurobiology of Learning and Memory, 75(3), 245-252.

Wiltgen, B. J., Sanders, M. J., Behne, N. S., \& Fanselow, M. S. (2001). Sex differences, context preexposure, and the immediate shock deficit in Pavlovian context conditioning with mice. Behavioral Neuroscience, $115,26-32$.

Young, S. L., Bohenek, D. L., \& Fanselow, M. S. (1994). NMDA processes mediate anterograde amnesia of contextual fear conditioning induced by hippocampal damage: Immunization against amnesia by context preexposure. Behavioral Neuroscience, 108, 19-29.

Zhang, W. N., Bast, T., \& Feldon, J. (2001). The ventral hippocampus and fear conditioning in rats: Different anterograde amnesias of fear after infusion of $N$-methyl-D-aspartate or its noncompetitive antagonist MK801 into the ventral hippocampus. Behavioural Brain Research, 126(12), 159-174.

Zola-Morgan, S., \& Squire, L. R. (1993). Neuroanatomy of memory. Annual Review of Neuroscience, 16, 547-563.

Received May 16, 2003

Revision received August 22, 2003

Accepted August 29, 2003 